\section{Diversity overrated}

SIR - Once again, the spectre of genetic depauperization has reared its head, this time overriding the possibility that introduced disease may threaten the last wild population of golden lion tamarins ${ }^{1}$. The News item in Nature reported that "plague is a risk we [the US National Zoo] feel we have to take to "maintain maximum genetic diversity". However, it is not clear that such a decision is justified.

There is general agreement that smaller populations are at greater risk of extinction than are larger populations ${ }^{2,3}$. However, there is also increasing understanding that this risk is more likely to come from demographic constraints than from genetic constraints ${ }^{3}$. Although there is considerable evidence that environmental factors, including epizootic diseases, have had catastrophic effects on wild populations ${ }^{2,4,5}$, there is a complete absence of examples of wild populations in which either inbreeding depression or a lack of genetic variability is known to have been primarily responsible for significant reductions in population size, much less extinction. On the contrary, there are numerous examples of wild populations that are both monomorphic and apparently healthy ${ }^{2}$.

The continued disproportionate attention given to genetic considerations is due in part to the considerable monetary and public relations investment that many zoos have made in presenting themselves as conservation centres. Evidence of their success in these efforts is provided by the 'News' article, where it is stated that "most conservation programmes are ... funded by zoos", which is simply untrue. It is also misleading to suggest that most zoos carry out reintroduction programmes. Rather, the goal of most zoos' captive breeding programmes appears to be the maintenance of captive populations, and only a handful have attempted to reintroduce endangered species into the wild.

All else being equal, there can be little doubt that genetic diversity is desirable. However, all is not equal, and poorly documented concerns about genetic diversity consume limited conservation resources and may also more directly threaten manipulated wild populations through disease transmission, outbreeding depression ${ }^{2,3}$ and translocation risks.

Truman P. Young Center for Population Biology and

Department of Botany, University of California,

Davis 95616, USA

1. Anderson, C. Nature 351, 89 (1991)

2. Simberlof, D. A. Rev. Ecol. Syst 19, 473-512 (1988).

3. Lande, R. Science 241, 1455-1460 (1988).

4. Harwood, J. \& Hall, A. Trends Ecol. Evol. 5, 254-257 (1990). 5. May, R. M. Nature 320, 13-14 (1986).

\section{War reparations}

SIR - United Nations' resolutions require Iraq to pay 30 per cent of its future oil revenues to compensate the countries affected by the recent invasion of Kuwait, but this does not cover compensation for the damage to nature. We suggest that a sum of money be guaranteed from Iraq's oil revenues to be used to turn part of the wastelands we saw on television into a scene of a green desert. The chlorophyll of the trees would turn the carbon dioxide added to the atmosphere by the burning oil wells into wood and green leaves.

There is groundwater in the layers underlying the sand dunes of the desert of Kuwait and southern Iraq ${ }^{1,2}$. The annual average rainfall is about $100 \mathrm{~mm}$. A certain percentage of the rainwater infiltrates into the porous sand, to form a shallow water table. Below this, mostly fresh, groundwater, there is brackish and saline water.

We do not think there is enough water for intensive irrigated agriculture, but we are positive that with the available quantity of rain falling on sands, the area can be turned into a 'savanna' of desert trees and bushes. The tree roots can catch part of the water before it evaporates from the surface or penetrates into the groundwater. The preliminary results from our research on the hydrology of forestation in arid zones, indicates that sand dunes (under similar climatic conditions to that of the Persian Gulf) can retain a planted forest of tamarisk trees. Moreover, we found that in the tree-covered area, more humidity is retained in the upper soil than in the area bare of trees. The roots go down to the depth of $10 \mathrm{~m}$ and reach the brackish groundwater, thus ensuring themselves with a safe water supply, even during years of drought.

\section{The Jacob Blaustein Institute for}

ARIE S. ISSAR EILON ADAR

Desert Research,

Ben Gurion University of the Negev, Sede Boker Campus,

84990, Israel

1. Burdon, D. T. Report to the Government of Kuwait (Kuwait 1966).

. Himidia, I. H. \& El Yaqubi, A. S. 3rd Seminar on Environment and Pollution (Kuwait University, Kuwait, 1977).

\section{Unwise after the events}

SIR - Your publication of the correspondence from E. Guthy (Nature 348, 670; 1990) and Frits Meijler (Nature 350, 268; 1991 ) and recently by Falk Koenemann (Nature 350, 648; 1991) and Rudolf Vrba (Nature 350, 648; 1991) is at the same time startling and perplexing.

I recognize the broad readership of your journal and its interest beyond mere scientific publications. It surprises me nevertheless that your journal provides space for a discussion on "German genes", on "national and racial characteristics" based on German history and for somewhat apologetic responses from German scientists born after 1950.

After the disastrous experiences of the past, is there really a need for a barely masked new racial view even when it originates from most tragic personal suffering and, though emotionally understandable, now inculpates subsequent generations?

What is more astonishing than the views of the individual authors is an editorial policy that provides a forum for discussions which are scientifically absurd and, in a unifying Europe, at best suited only to stir up emotions.

It might be a good idea to apply to such letters some of the principles supposed to be used for scientific publications.

Harald zur Hausen

Deutsches Krebsforschungszentrum,

Im Neuenheimer Feld 280,

6900 Heidelberg 1 ,

Germany

SIR - I read with interest and irony the debate in your columns on the new Germany. But the debate seems futile.

Certainly we could ask such questions about many countries . . . . Is there a new United States or is it the same country that practised genocide on its Indians, was the first and only country to use nuclear bombs in war, and practised dioxin warfare in Vietnam ... ? Is there a new United Kingdom or the same one that practised genocide on Australian Aborigines, invented concentration camps in South Africa, and carried out saturation bombing with phosphorus bombs for three days in a row in Hamburg and Dresden ... ? Is there a new Belgium since our conquest of the Congo? Do you want me to continue? In a civilized world one does not condemn the children for the crimes of their fathers.

Universite Libre de Bruxelles,

J. E. DUMONT Campus Hopital Erasme,

Route de Lennik 808 ,

1070 Bruxelles,

Belgium

\section{Thinking on the run}

SIR - The term 'run' has come to connote an analytical session on a given instrument, conducted over a period of time. We have questioned several of our colleagues, and nobody knows the derivation of this now well established vernacular word. Does anybody know?

Geography Department,

RONALD I. DORN

Chemistry Department,

Arizona State University,

Tempe, Arizona 85287-0104, USA 